\title{
Adaptive V/f-Based Control for Induction Machines in Distributed Electric Propulsion Systems
}

\author{
M. Sztykiel, R. Pena-Alzola, C. Jones, P. Norman, \\ S. Galloway, G. Burt \\ Department of Electronic and Electrical Engineering \\ University of Strathclyde \\ Glasgow, UK \\ $\underline{\text { michal.sztykiel@strath.ac.uk, rafael.pena- }}$ \\ alzola@strath.ac.uk, catherine.jones@strath.ac.uk, \\ patrick.norman@strath.ac.uk
}

\begin{abstract}
- a novel adaptive control function is presented as an improvement to the classic volts per hertz (V/f) technique where high torque oscillations occur during rapid changes of the rotating speed. The proposed adaptive feature of an improved controller limits torque oscillations by injecting a pulse and imposing the pre-determined bands on a voltage reference waveform whenever the scheduled change in speed occurs. This adaptive function has been integrated with the closed-loop V/f control scheme, subsequently modelled and evaluated numerically using transient simulation studies, as well as experimentally using an induction machine drive test rig. The results have shown that the proposed adaptive element provides an improved dynamic performance for using the V/f method, which is required in compact distributed drive systems with single voltage source inverter (VSI) controlling multiple interconnected motors.
\end{abstract}

Keywords—closed loop V/f control; induction machine; CSVPWM; multiple motors

\section{INTRODUCTION}

The need for next generation aircraft to have reduced fuel consumption, noise level and $\mathrm{CO}_{2}$ emissions [1] has stimulated the development of partial and full electrification concepts for propulsion. The trend towards the increased use of electrical power to meet these target performance requirements has resulted in an ongoing development of compact high power electrical components [2]. Hybridelectric aircraft concept has been proposed as a way to meet these performance targets in the longer term.

Among the available machine drive designs required for electric propulsion, variable-speed induction motors have become an attractive option, as they are extremely durable and cost less to produce compared to other types of motors. Permanent magnet synchronous machines are also highly suited to aero-electrical applications due to their high torque density enabling weight savings [3] and high efficiency. According to [4], high speed permanent magnet machines can achieve typically up to $33 \%$ higher torque density than an equivalent high speed induction machine for aerospace applications.

This work has been carried out as part of the Rolls-Royce University Technology Centre research programmes at the University of Strathclyde and Nanyang Technological University.

\author{
S. Mukherjee \\ Electrical Power and Control Systems (EPACS) \\ Rolls-Royce@NTU Corporate Lab \\ Singapore \\ suvajit@ntu.edu.sg
}

However, uncertainty in the long term availability of rare earth materials within the permanent magnets combined with high and volatile cost of such machines [5] indicates a need to investigate permanent magnet-free electrical machine alternative options for future hybrid-electric propulsion systems with multiple distributed fans.

The development of speed control drives for induction motors is a well-established topic and a considerable research has already been reported. References [6]-[9] give a concise description of the various control schemes available for speed control drives, which vary in terms of complexity and performance. With the introduction of solid-state power converters, a number of these control methods have been applied to a number of current day variable-speed drives.

The first control method for the induction motor drives was proposed by Abbondanti [6], who developed the constant Volts per Hertz (V/f) control. Due to its simplicity, the V/f method is well understood and requires little motor data for controlling the speed. In comparison with existing vector-based techniques that have been developed since the introduction of vector control theory by Blaschke [7], the conventional V/f method results in a comparably worse dynamic behavior. This is because of uncontrollable magnetic flux, which results in air gap flux linkages deviating from their set values. In vectorbased control methods, the magnetic flux is normally estimated to better optimize the position of a voltage reference signal.

A method to improve the dynamic performance of $\mathrm{V} / \mathrm{f}$ control has been presented by Liu [8], where the improved structure adopts some concepts from the vector control. The discussed method utilizes a current damper control to suppress the oscillations during transients and therefore requires current sensors. Similarly, Yang [9] proposed a method where dynamics can be mitigated by the compensation of reactive currents in the d-q plane, which also requires phase current measurements.

Due to improved dynamics and performance at low speed, most of the research has more recently focused on vector control schemes where the required voltage signal can be accurately predicted from sophisticated algorithms. However, only the scalar-based V/f method allows simultaneous speed control of multiple induction motors operating in parallel and 
controlled using a single voltage source inverter (VSI). In such an arrangement, vector-based technique can be utilized only for individual control of a single machine. Consequentially, the speed cannot be changed in a controlled manner for two or more machines simultaneously. When using V/f method, this limitation can be mitigated provided the identical speed is appied.

The discussed arrangement, where all motors share an identical fan shaft speed makes the configuration feasible for a turboelectric distributed propulsion system (TeDP) introduced by NASA in 2005 [10].

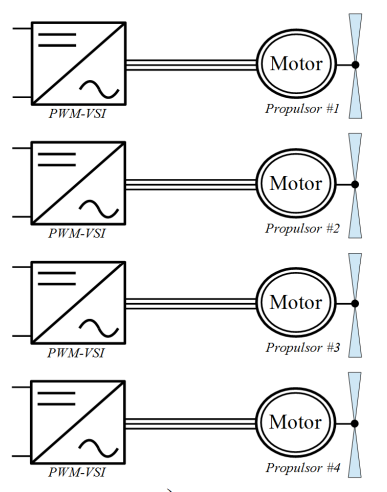

a)

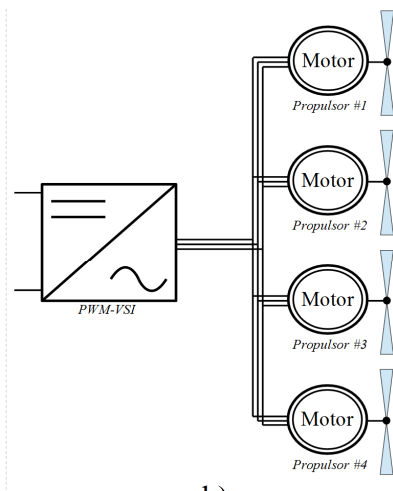

b)
Fig. 1. Electric propulsion configurations: a) multiple VSIs; b) single VSI.

Fig. 1 illustrates two TeDP concepts, where multiple motors that drive fans are run in parallel. The configuration with a single centralized VSI offers several advantages to the distributed VSIs, such as lower cost, size, weight and maintenance requirements [11] of the electric propulsion system. However, it also increases vulnerability of the propulsion system to a single converter failure. For such a configuration, the VSI controller should ideally compensate any dynamic torque response caused by excessive wind changes at different altitudes.

In this paper, a new method to improve the dynamic performance of $\mathrm{V} / \mathrm{f}$ controlled induction motor drives is presented. The improved prediction-based compensation method does not require any current sensors and can be integrated with a classic closed-loop V/f method. This allows more precise speed regulation while maintaining simplicity of an open-loop V/f technique, as tuning of the VSI to the motor is not required.

The presented technique adopts concepts of a dynamic saturation-based control, which divides a V/f linear characteristic into individual saturation sectors. Each sector is used to predict the location of a voltage reference in the first instance, which allows resetting and narrowing of the upper and lower limiters of a proportional-integral (PI) speed controller. The proposed improvement to V/f control has been validated by simulation and experimental results.

This section describes the developed model of a baseline induction machine drive, to enable the comparison of the improved V/f control with conventional V/f control. In addition, the developed model is used to compare the steady and dynamic torque response with the response obtained from an induction machine drive experimental test rig.

The schematic representation of an induction machine drive model is illustrated in Fig. 2. It consists of a six-switch VSI [12] and an induction motor. A Conventional Space Vector Pulse-Width-Modulation (CSV-PWM) modulator was implemented along with classic closed-loop V/f control. The modelling of sensors is omitted in this paper, while communication channels are modelled with signal samplers.

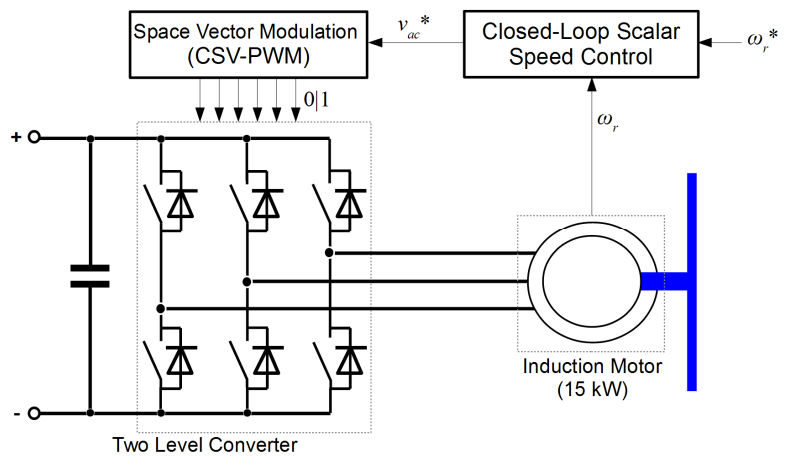

Fig. 2. Schematic diagram of baseline induction machine drive.

\section{A. Induction Motor Model}

A squirrel-cage induction motor is modelled with a basic fourth order state-space model developed by Bottura [13] using voltage-current equations in stator referred $\mathrm{d}-\mathrm{q}$ coordinates, which are expressed in Laplace domain for stator $v_{d q s}$ and rotor $v_{d q r}$ quantities as:

$$
\left[\begin{array}{c}
v_{q s} \\
v_{d s} \\
v_{q r} \\
v_{d r}
\end{array}\right]=\left[\begin{array}{cccc}
R_{s}+s \cdot L_{s} & \omega \cdot L_{s} & s \cdot L_{m} & \omega \cdot L_{m} \\
-\omega \cdot L_{s} & R_{s}+s \cdot L_{s} & -\omega \cdot L_{m} & s \cdot L_{m} \\
s \cdot L_{m} & \left(\omega-\omega_{r}\right) \cdot L_{m} & s \cdot L_{r} & R_{r}+\left(\omega-\omega_{r}\right) \cdot L_{r} \\
\left(\omega-\omega_{r}\right) \cdot L_{m} & s \cdot L_{m} & \left(\omega-\omega_{r}\right) \cdot L_{r} & s \cdot L_{r}
\end{array}\right] \times\left[\begin{array}{c}
i_{q s} \\
i_{d s} \\
i_{q r} \\
i_{d r}
\end{array}\right]
$$

where $R_{s}(\Omega)$ and $R_{r}(\Omega)$ are resistances of stator and rotor windings and $L_{s}(H), L_{r}(H)$ are accordingly stator and rotor inductances, which consist of a leakage and a magnetizing inductance $L_{m}(H) . \omega\left(\mathrm{rad} \cdot \mathrm{s}^{-1}\right)$ represents stator reference frame angular speed and the rotor angular speed is $\omega_{r}\left(\mathrm{rad} \cdot \mathrm{s}^{-1}\right)$. Finally, $s$ stands for Laplace operator.

Based on the determined d-q currents for stator $i_{d q s}(A)$ and rotor $i_{d q r}(A)$ circuits from (1), the electromagnetic torque $T_{E M}$ $(N \cdot m)$ invariant form of the Clarke's Transform is obtained from

$$
T_{E M}=\frac{3}{2} \cdot p \cdot L_{m} \cdot\left(i_{d r} \cdot i_{q s}-i_{d s} \cdot i_{q r}\right)
$$

where $p$ represents the number of machine pole pairs.

\section{B. CSV-PWM Modulator}

For the PWM switching of the VSI, a CSV-PWM technique developed by Van der Broeck [14] has been selected due to its higher utilization of the dc-bus voltage compared to other methods. Fig. 3 illustrates the resulting reference voltage waveforms from the modelled CSV-PWM modulator, yielding up to $15 \%$ higher fundamental line voltage for a given DC bus compared to a sinusoidal PWM method. 


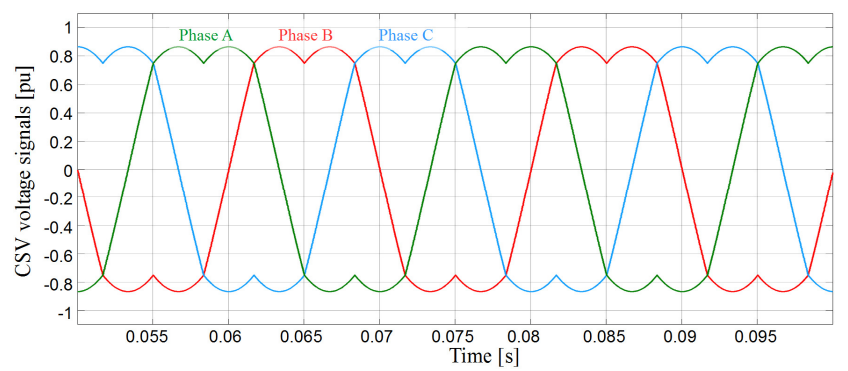

Fig. 3. Schematic diagram of baseline induction machine drive.

\section{Classic Closed-Loop V/f Control}

The closed-loop V/f method offers a more precise solution to controlling the speed than the open-loop V/f method, as it responds immediately to any detected speed changes. Fig. 4 illustrates the typical structure of a modelled closed-loop V/f control [15], which includes an encoder for speed measurements, a PI regulator with anti-windup based on clamping [16] and $V / f$ linear characteristic.

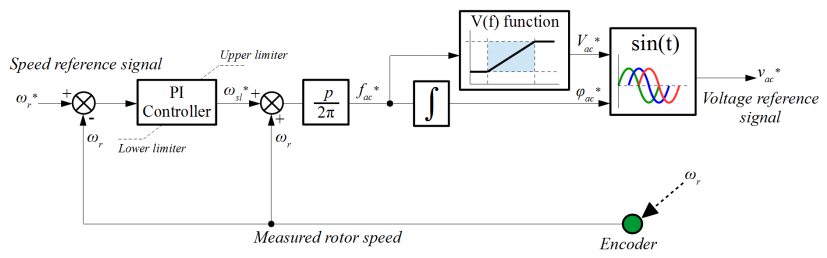

Fig. 4. Schematic diagram of a conventional V/f control technique.

The actual rotor speed $\omega_{r}$ is compared with the reference value $\omega_{r}{ }^{*}$, and the difference is compensated by a PI controller, which regulates the actual slip speed $\omega_{s l}{ }^{*}$. The $\omega_{s l}{ }^{*}$ is then added to the positive feedback rotor speed $\omega_{r}$ to determine the required stator reference speed. By using the $V(f)$ linear function, the stator reference speed is translated to the actual voltage magnitude reference signal $V_{a c}{ }^{*}$. The $V_{a c}{ }^{*}$ signal then is correlated with three sinusoidal functions displaced by 120 degrees with a frequency of $f_{a c}{ }^{*}$. The output signals from the sinusoidal function represent the reference $v_{a c}{ }^{*}$, which is fed to the CSV-PWM modulator.

Fig. 5 illustrates the classic $V / f$ characteristic, which is normally limited by minimum and maximum operating frequencies [15].

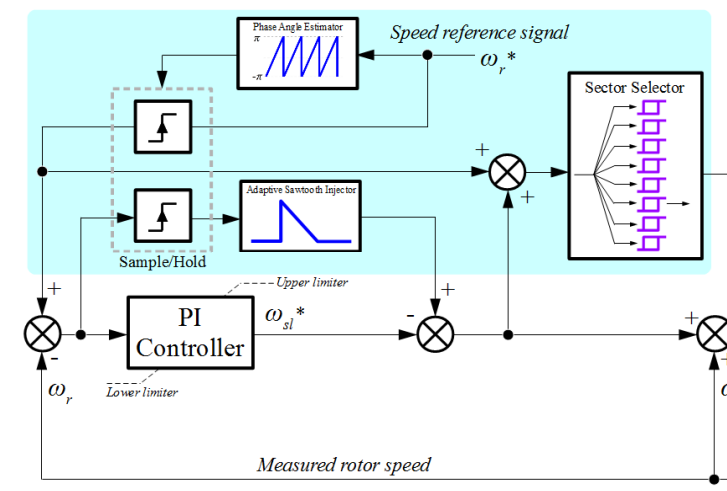

Fig. 6. Schematic diagram of a proposed adaptive V/f control technique.

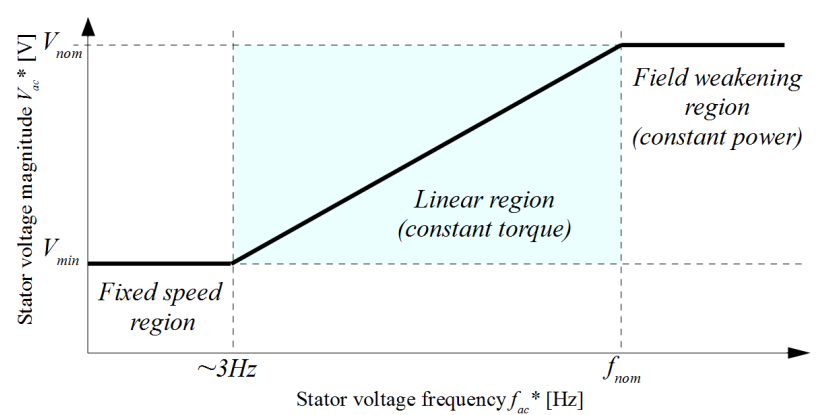

Fig. 5. Classic V/f linear characteristic within the constant torque region.

Below a minimum operating frequency of circa $3 \mathrm{~Hz}$ [17], the constant V/f ratio cannot be satisfied due to the influence of a voltage drop introduced by stator resistance.

\section{DESIGN OF THE PROPOSED ADAPTIVE ClOSED-LOOP V/F CONTROLLER}

For this paper, a controller based on adaptive saturation limiter from Fig. 6 has been developed and modelled to improve the dynamic performance of a conventional V/f control, which operates in a linear region of its $V(f)$ function. The developed adaptive saturation limiting technique can be used to minimize dynamic oscillations during rapid changes of a reference speed $\omega_{r}^{*}$.

\section{A. Phase Angle Estimator}

The role of a phase angle estimator is to apply a controllable delay with each change of the input reference signal. The delay is used to synchronize the change of an input speed with the actual rotor angle position. The reference speed change is realized in a phase angle estimator only at the positive zerocrossing of a voltage reference, which corresponds to $\varphi_{r}=0$. Fig. 7 illustrates the implementation of a phase angle estimator using comparators, sample/hold blocks and logic gates. The comparators detect a positive increase of a phase angle at each zero-crossing between $-\pi$ and $+\pi$.

The indication of the positive zero-crossing is required to ensure that the adaptive selection of saturation limiters, along with the saw tooth pulse signal injection, are to be performed only at the positive zero-crossing of a rotor phase angle. Such synchronized operation prevents rapid torque oscillations when control signals and band limits adapt to new operating conditions.

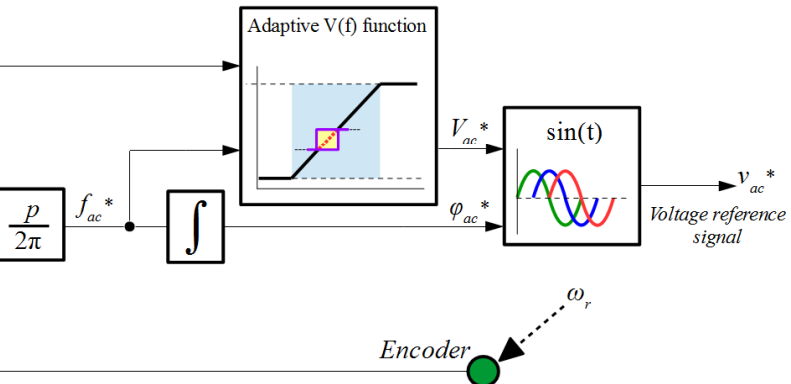




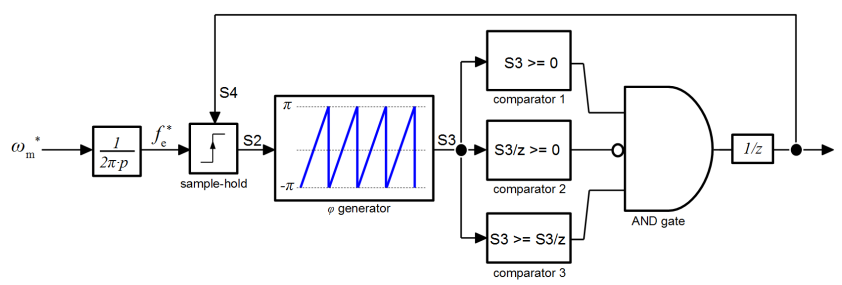

Fig. 7. Schematic diagram of a modelled phase angle estimator.

The maximum delay of 0.33 s occurs with the changes of a speed reference at $f_{a c} *=3 \mathrm{~Hz}$. Due to relatively high inertia of large machines, it is expected that such delay will not substantially impact the overall controllability performance.

\section{B. Adaptive Sawtooth Pulse Generator}

During the reference speed step change, an adaptive sawtooth pulse is injected to generate an improved control signal. The pre-determined pulse injection of opposite sign compensates the initial difference between measured and reference signals.

The proposed linear prediction-based compensation improves both the electromagnetic torque stability and the response time of the control. The height of each pulse is proportional to the actual difference between the measured and reference speeds $\omega_{r}{ }^{*}-\omega_{r}$ at the time of a positive zerocrossing: $\varphi_{r}=0$.

\section{Adaptive Adjustment of Dynamic Saturation Limits}

The saturation limits are used to limit the variations of the voltage reference magnitude $V_{a c}{ }^{*}$ across the $V / f$ characteristic, which improves the stability during the transient speed step changes. The multiple saturation limiters essentially impose adaptive dynamic limiters to the PI controller output, the margins of which vary with the actual rotor speed.

The selection process takes place at each positive zerocrossing, and is synchronized with a saw-tooth pulse injection. The saturation upper and lower levels are determined on the basis of the reference speed $\omega_{r}{ }^{*}$ and the determined actual slip $\omega_{s l}{ }^{*}$. For each saturation sector, the distance between upper and lower limits must be set higher than the value of a fullload slip at nominal speed, which is typically $0.05 \mathrm{pu}$ [18]. This constraint also imposes a limit on the number of saturation sectors $N_{(-)}$being available for the selection.

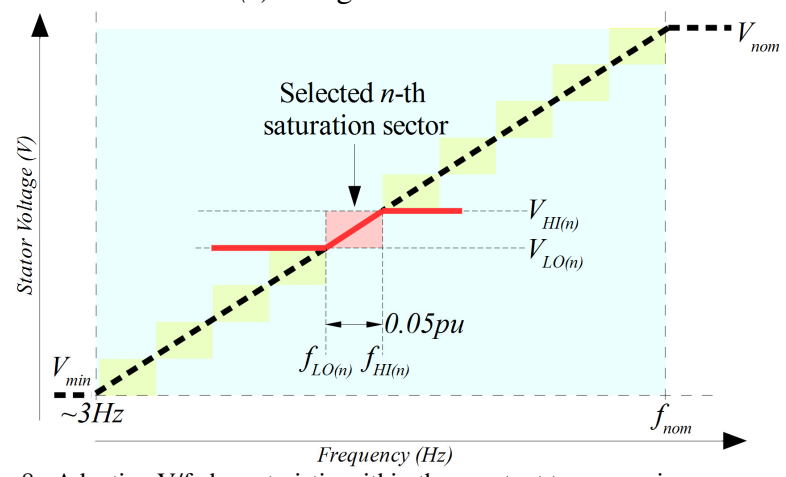

Fig. 8. Adaptive V/f characteristic within the constant torque region.
In accordance with Fig. 8 , the bands of $n$-th sector can be calculated from:

$$
\begin{aligned}
& V_{H I(n)}=A \cdot f_{H I(n)}+B \\
& V_{L O(n)}=A \cdot f_{L O(n)}+B
\end{aligned}
$$

where $A(\mathrm{~V} / \mathrm{Hz})$ and $B(\mathrm{~V} / \mathrm{Hz})$ represent parameter constants defined as:

$$
\begin{aligned}
& A=\frac{V_{\text {nom }}-V_{\text {min }}}{f_{\text {nom }}-3 H z} \\
& B=V_{\text {nom }}-3 H z \cdot \frac{V_{\text {nom }}-V_{\text {min }}}{f_{\text {nom }}-3 H z}
\end{aligned}
$$

Upper and lower frequency bands $f_{H I(n)}(H z)$ and $f_{L O(n)}(H z)$ for $n$-th available saturation sector are calculated from:

$$
\begin{aligned}
& f_{L O(n)}=3 H z+(n-1) \cdot 0.05 \cdot f_{\text {nom }} \\
& f_{H I(n)}=n \cdot 0.05 \cdot f_{\text {nom }}
\end{aligned}
$$

on condition that $n \leq N$ and:

$$
\frac{f_{\text {nom }}}{N}>0.05 p u
$$

In order to achieve best effect in limiting torque and current oscillations that may from the excessive variations of voltage reference signal $V_{a c} *$ during motor speed step changes, the adaptive controller should ideally operate with maximum permissible number of sectors (i.e. $n=N$ ).

\section{SIMULATION AND EXPERIMENTAL RESULTS}

This section presents the validation of the described adaptive control scheme, which has been modelled with a motor drive unit in Matlab/Simulink. The motor drive model includes a fully-switched converter from Fig. 2 and assumes no saturation occurs for the squirrel cage machine model. The performance of an adaptive control algorithm is evaluated by comparing it with the classic closed-loop V/f control method. Once validated through simulations, the response of the model has been compared with the response of a motor drive test rig.

\section{A. Simulation-based performance comparison with closed- loop V/f control scheme}

The modelled conventional control scheme from Fig. 4 includes a controller with proportional and integral gains. Table 1 presents parameter values of the developed induction drive model. Simulation results are compared separately during rapid speed change under full- and no-load conditions.

TABLE I

SPECIFICATION OF A MATLAB/SIMULINK MACHINE DRIVE MODEL

\begin{tabular}{|l|l|}
\hline \multicolumn{1}{|c|}{ Parameter } & \multicolumn{1}{c|}{ Value } \\
\hline Nominal power & $P_{n o m}=15 \mathrm{~kW}$ \\
\hline Nominal speed & $\omega_{r(n o m)}=1465 \mathrm{RPM}$ \\
\hline Nominal voltage $(\mathrm{DC})$ & $V_{d c}=550 \mathrm{~V}$ \\
\hline Switching frequency & $f_{s w}=5 \mathrm{kHz}$ \\
\hline Rotor and stator resistances & $R_{s}=279 \mathrm{~m} \Omega ; \quad R_{r}=265 \mathrm{~m} \Omega$ \\
\hline Rotor $\left(L_{r}\right)$, stator $\left(L_{s}\right)$ and mutual & $L_{s}=2.81 \mathrm{mH} ; \quad L_{m}=23.2 \mathrm{mH}$ \\
$\left(L_{m}\right)$ inductances & $L_{r}=3.70 \mathrm{mH} ;$ \\
\hline Number of pole pairs & $p=2$ \\
\hline PI controller gains & $K_{p}=0.6 ;$ \\
\hline Number of saturation sectors & $N=8$ \\
\hline
\end{tabular}




\section{1) Rapid speed increase under no-load conditions}

Fig. 9 illustrates the response of electromagnetic torque $T_{E M}$ and mechanical speed $\omega_{r}$ when the input reference signal $\omega_{r} *$ is changed at $t=1 \mathrm{~s}$ from $200 \mathrm{RPM}$ to nominal $1465 \mathrm{RPM}$ and mechanical load $T_{m}$ is $0 \mathrm{Nm}$. The response has been recorded both for traditional closed-loop V/f control, and for the improved adaptive controller described in this paper.

As indicated in Fig. 9, with classic V/f control, a sudden reference speed change results in heavy torque oscillations. For the induction motor with parameters described in Table 1, it results in a peak transient torque of $242 \mathrm{Nm}$ occurring $0.01 \mathrm{~s}$ after the step change to the reference rotor speed takes place. Such an oscillation will impose an excessive mechanical stress on the induction motor, which ultimately may result in the premature failure of the motor. Similarly, due to non-linear thermal characteristics the converter switches will need to be overrated to reliably withstand thermal stress imposed by the induced excessive di/dt current pulses.

When an adaptive controller is used with identical PI controller settings, the peak torque overshoot during the speed step change drops to $103 \mathrm{Nm}$ (within $5 \%$ of the steady-state value: $\left.T_{E M(\text { nom })}=97.77 \mathrm{Nm}\right)$.
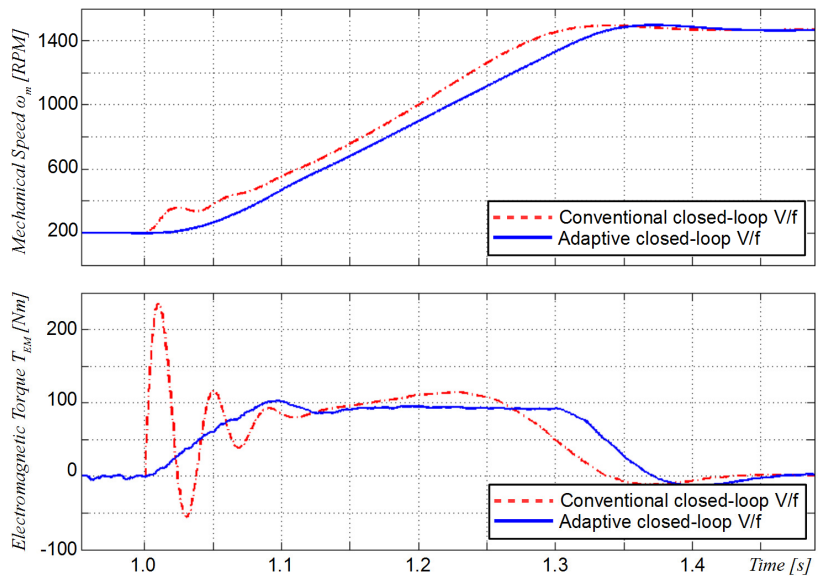

Fig. 9. Speed and torque transient response during no-load $\omega_{r}{ }^{*}$ change.

\section{2) Rapid speed change under full-load conditions}

Fig. 10 illustrates the system response when the reference rotor speed is changed and when the motor is fully loaded with mechanical power of $15 \mathrm{~kW}$. Similar to the no-load condition, the electromagnetic torque oscillations occur in a machine drive equipped with a conventional closed-loop V/f controller immediately after the signal reference $\omega_{r} *$ is changed from 200 RPM to 1465 RPM.

The registered peak value of electromagnetic torque is 218 $\mathrm{Nm}$, and occurs at $1.01 \mathrm{~s}$. With an implemented adaptive control technique, the induced momentary torque pulse can be reduced to $158 \mathrm{Nm}$, significantly reducing the mechanical stress placed on the mechanical system.

Similarly to the speed increase, high torque oscillations occur in a classic V/f control scheme when speed is rapidly decreased. Fig. 11 shows the speed and torque characteristics when the machine speed decreases from 1465 RPM to 800 RPM under full loading conditions.

The proposed adaptive V/f control allows $425 \%$ reduction in the peak torque value. However, the actual speed becomes $200 \mathrm{RPM}$ after $0.5 \mathrm{~s}$, which takes $0.3 \mathrm{~s}$ longer when comparing to the classic V/f scheme.
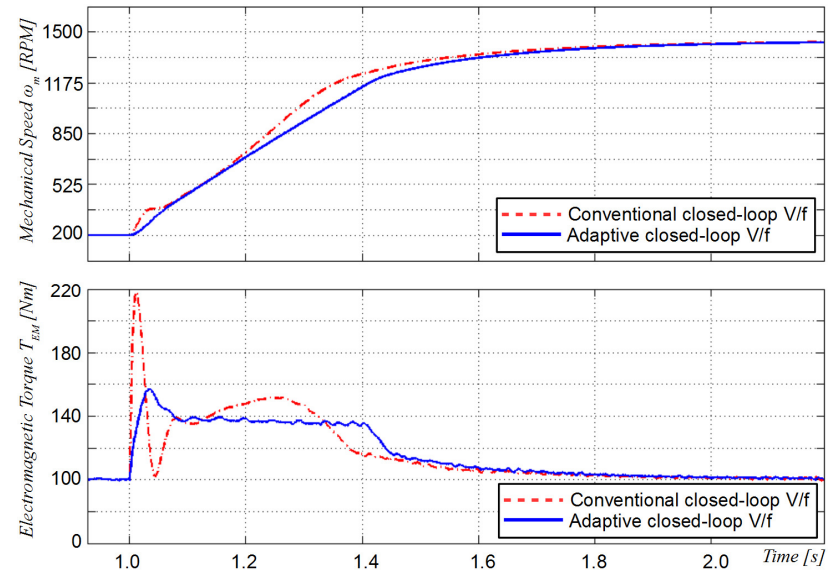

Fig. 10. Speed and torque transient response during full-load $\omega_{r}{ }^{*}$ change.
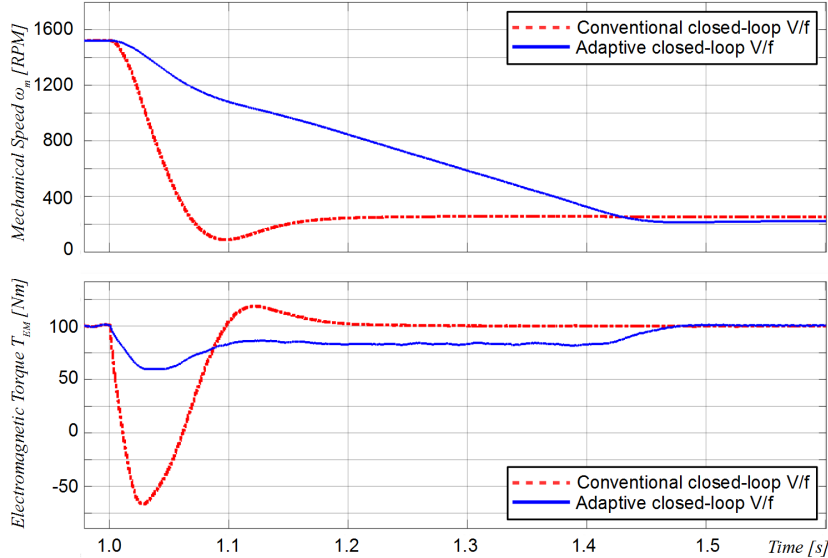

Fig. 11. Speed and torque transient response during full-load $\omega_{r}{ }^{*}$ change.

\section{B. Hardware-based performance comparison with a modelled adaptive V/f control}

In order to validate the modelled induction machine drive and the adaptive V/f control, the transient response generated by the model has been compared to results obtained from an experimental test rig in the laboratory. Both transient and steady-state responses of the simulated induction machine drive with adaptive V/f control have been validated. PI regulator gains, accordingly $K_{\mathrm{p}(\omega)}$ and $K_{\mathrm{i}(\omega)}$ have been determined based on symmetrical optimum method [19].

The laboratory hardware consists of a $15 \mathrm{~kW}$ induction motor drive interfaced with an MEA dynamometer [20], which enables control of the mechanical load connected to the motor. The VSI controller has been designed using Code Composer Studio for a Texas Instruments TMS320F28335 DSP board [22]. The speed of the motor is controlled using the V/f control methods described in this paper via the six 
switch inverter SEMIKRON SKAI 45 A2 GD12-WCI [23]. The described laboratory set up is shown in Fig. 12.

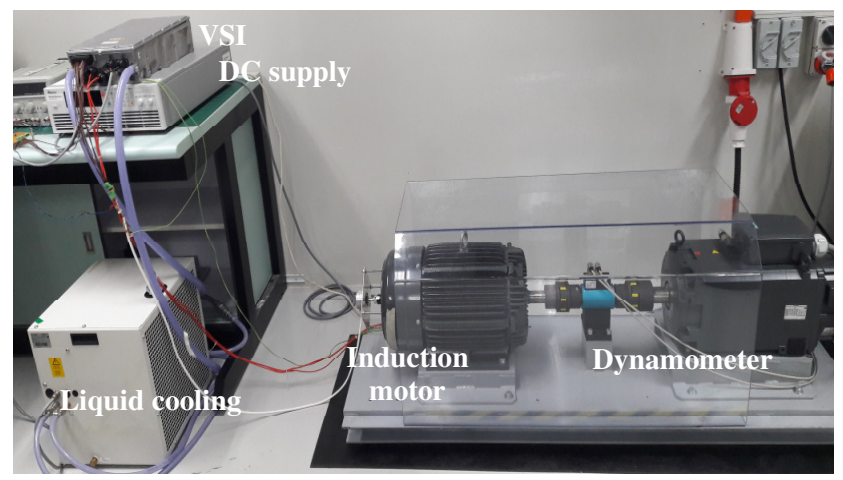

Fig. 12. Machine drive test rig for validation of an adaptive controller.

TABLE II

SPECIFICATION OF $15 \mathrm{KW}$ MACHINE DRIVE TEST RIO

\begin{tabular}{|c|c|}
\hline Component & Specification \\
\hline $\mathrm{AC} / \mathrm{DC}$ Inverter & $\begin{array}{l}\text { Semikron SKAI } 45 \text { A2 GD12-WCI [23] } \\
\text { six-switch }\left|v_{\mathrm{dc}}=550 \mathrm{~V}\right| C_{\mathrm{dc}}=1.25 \mathrm{mF}\end{array}$ \\
\hline $\begin{array}{l}\text { Induction Squirrel } \\
\text { Cage Motor }\end{array}$ & $\begin{array}{c}\text { TECO AEEB (1465 RPM) [24] } \\
\text { 4-pole }|P=15 \mathrm{~kW}| v_{\mathrm{ac}}=380 \mathrm{~V} \mid J=0.09 \mathrm{~kg} \cdot \mathrm{m}^{2}\end{array}$ \\
\hline Control Circuit & $\begin{array}{l}\text { Adaptive Closed-Loop V/f Control } \\
\text { PI regulator gains: } K_{\mathrm{p}(\omega)}=0.6 \mid K_{\mathrm{i}(\omega)}=2\end{array}$ \\
\hline Modulator & $\begin{array}{l}\text { CSV-PWM }[14] \\
f_{\text {switching }}=5 \mathrm{kHz}\end{array}$ \\
\hline Sensor & $\frac{\text { Hengstler RS0-532-315 }}{f_{\text {sampling }}=300 \mathrm{kHz}}[25]$ \\
\hline
\end{tabular}

\section{1) Steady-State Performance}

Fig. 13 illustrates an example time-domain waveform and harmonic spectrum of the DC current when the machine rotates at its nominal speed of 1465 RPM. In this example, the machine is loaded with $T_{m}=40 \mathrm{Nm}$. The distribution of current harmonics is similar between the machine drive test rig and its equivalent model using an adaptive control circuit.
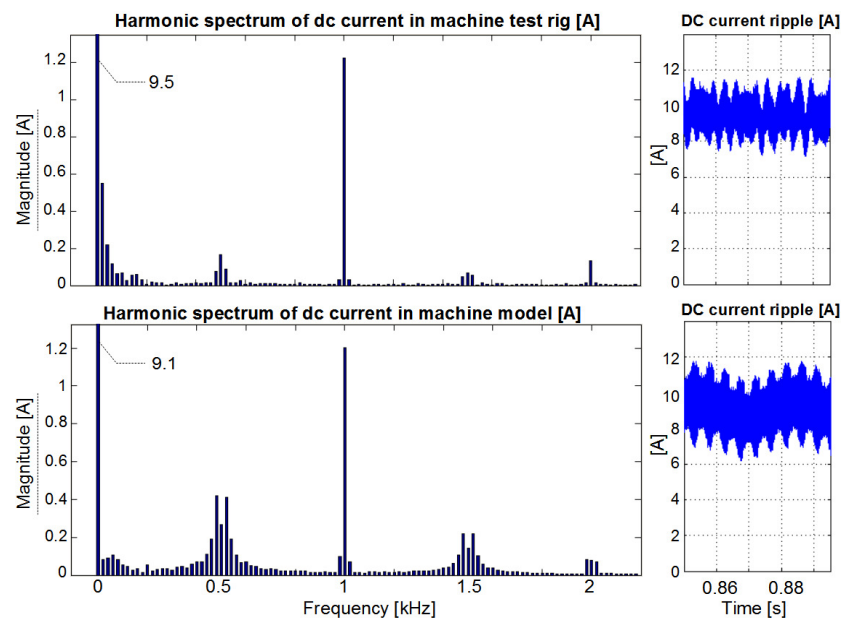

Fig. 13. Harmonic spectrum of converter dc link currents from machine test rig (top) and its equivalent transient model with adaptive V/f control (bottom).

The dominant harmonics registered are the multiples of $f_{\text {switching }}=0.5 \mathrm{kHz}$, with the most significant being the second- order harmonic. The dc component of the current varies less than $3 \%$. Higher ripple in the simulated current occurs due to lack of a parasitic inductance, which is present when interconnecting physical hardware components.

\section{1) Dynamic Performance}

The dynamic performance of the model was validated by applying a change in mechanical load by $30 \%$, as well as a step response of reference speed $\omega_{r}^{*}$. Fig. 14 illustrates an example of the ac current and speed variations when the torque changes from 40 to $10 \mathrm{Nm}$ using the same controller settings. It can be seen that there is excellent correlation between the simulated and experimental results for the dynamic performance.
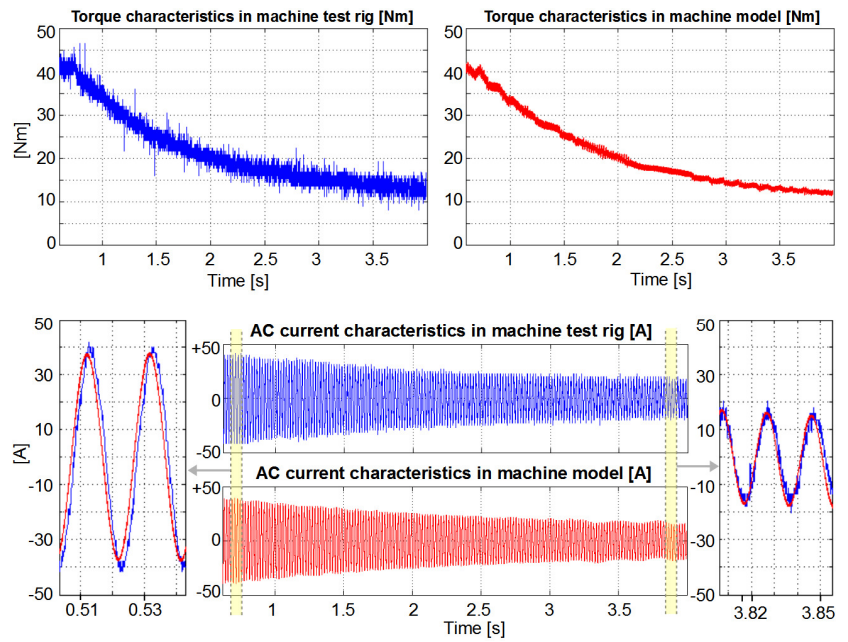

Fig. 14. Torque and ac current $i_{a c}$ characteristics from machine test rig (measured) and its equivalent transient model with adaptive V/f control during torque $T_{m}$ step change.

\section{CONCLUSIONS}

If induction motors are to be considered a viable alternative to permanent magnet motors for future aircraft applications, then the adaptive V/f control presented in this paper may offer a viable control method for hybrid electric propulsion systems with multiple fan shaft drives.

The proposed improved control significantly limits torque oscillations during rapid speed changes at high loading conditions by using an adaptive saturation sector selection. This significantly reduces the mechanical stress on the induction motor, resulting in increased lifetime and expected improved reliability of these systems. This is particularly important when considering the potential flight critical nature of these electrical loads for hybrid electric aircraft.

This paper has successfully demonstrated the concept of an adaptive V/f control at low power levels. However the authors continue to work on developing the next stage of this concept. This includes firstly analysis of controller performance over distributed multiple motors and secondly the investigation of the scalability of these induction motor based systems and associated control to the megawatt power levels associated with near term hybrid electric aircraft. 


\section{REFERENCES}

[1] B. B. Choi, "Propulsion Powertrain Simulator: Future turboelectric distributed-propulsion aircraft.," IEEE Electrification Mag., vol. 2, no. 4, pp. 23-34, Dec. 2014.

[2] B. Sarlioglu and C. T. Morris, "More Electric Aircraft: Review, Challenges, and Opportunities for Commercial Transport Aircraft," IEEE Trans. Transportation Electrification, vol. 1, no. 1, pp. 54-64, June 2015.

[3] A. Borisavljevic, H. Polinder and J. A. Ferreira, "On the Speed Limits of Permanent-Magnet Machines," IEEE Trans. Industrial Electronics, vol. 57, no. 1, pp. 220-227, Jan. 2010.

[4] Ma Xiaohe et al., "Review of high speed electrical machines in gas turbine electrical power generation," TENCON 2015 - 2015 IEEE Region 10 Conference, Macao, 2015, pp. 1-9.

[5] L. Chen, D. Hopkinson, J. Wang, et al., "Reduced Dysprosium Permanent Magnets and Their Applications in Electric Vehicle Traction Motors," IEEE Trans. Magnetics, vol. 51, no. 11, pp. 1-4, Nov. 2015.

[6] A. Abbondanti, "Flux control system for controlled induction motors," U.S. Patent 3909 687, 1975

[7] F. Blaschke, "The principle of field orientation as applied to the new transvektor closed-loop control system for rotating-field machines," Siemens Rev., vol. 34, pp. 217-220, 1972.

[8] Y. Liu and B. Piepenbreier, "Improvement of dynamic characteristic for V/f controlled induction motor drive system," Int. Symposium on Power Electronics, Electrical Drives, Automation and Motion, pp. 707$712,2014 .$.

[9] R. Yang, W. Chen, Y. Yu, at al., "Stability improvement of V/F controlled induction motor driver systems based on reactive current compensation," Int. Conf. on El. Machines and Systems, pp. 88-90, 2008.

[10] J. Welstead and J.L. Felder, "Conceptual Design of a Single-Aisle Turboelectric Commercial Transport with Fuselage Boundary Layer Ingestion," 54 ${ }^{\text {th }}$ AIAA Aerospace Sciences Meeting, USA, 2016

[11] A. G. Patel, "Controlling Multiple Motors with One VFD," Rockwell Automation, Feb. 2017.

[12] E. Santos and E. Silva, "Advanced Power Electronics Converters: PWM Converters Processing AC Voltages," Wiley-IEEE Press, 2015, pp. 25-50.

[13] C.P. Bottura and S.A Filho, "A Parameter Space Approach for State Space Induction Machine Modelling and Robust Control," Brazillian Soc. Of Automatics (SBA) J. Controls \& Automation, vol. 11, no. 2, Aug. 2000.

[14] H.W. Van Der Broeck, H. Skudelny and G. Stanke, "Analysis and realization of a pulsewidth modulator based on voltage space vectors", IEEE Trans. Ind. Applic., vol. 24, no.1, pp.142-150, Jan/Feb 1998.

[15] Z. Zhang, Y. Liu and A.M. Bazzi, "An improved high-performance open-loop V/f control method for induction machines," IEEE Applied Power Electronics Conf. and Exposition (APEC), pp. 615-619, 2017.

[16] Choi, J., Lee, S.: 'Antiwindup strategy for PI-type speed controller', IEEE Trans. Industrial Electronics, 2009, 56, (6), pp. 2039-2046

[17] K. Koga, R. Ueda, and T. Sonoda, "Achievement of high performances for general purpose inverter drive induction motor system," in Conf. Rec. IEEE-IAS Annu. Meeting, pp. 415-425, 1989.

[18] U.A. Orji, Z. Remscrim, C. Schantz, et al. "Non-intrusive induction motor speed detection," IET Electr. Power Appl., vol. 9, no. 5, pp. 388396, 2015.

[19] V. Blasko and V. Kaura, "A new mathematical model and control of a three-phase AC-DC voltage source converter," IEEE Trans. on Power Electronics, vol. 12, no. 1, pp. 116-123, Jan 1997.

[20] MEA RDS Regenerative Dynamometer Test Systems Brochure, MEA Testing Systems Ltd., Netanya, Israel.

[21] R. Kumar, S. Das, P. Syam and A. K. Chattopadhyay, "Review on model reference adaptive system for sensorless vector control of induction motor drives," in IET Electric Power Applications, vol. 9, no. 7, pp. 496-511, 2015.

[22] TMS320F2833x, TMS320F2823x Digital Signal Controllers (DSCs) Datasheet, Texas Instruments Inc., USA, 2016. [Online]. Available: www.ti.com

[23] SKAI 45 A2 GD12-W12DI Datasheet, SEMIKRON Elektronik GmbH, Germany, 2011. [Online]. Available: www.semikron.com

[24] Three Phase Squirrel Cage Induction Motor Datasheet, TECO Electric \& Machinery (PTE) Ltd., Singapore, 2011. [Online]. Available: www.teco.com.sg
[25] RI58-D Hollow-Shaft Encoders Datasheet, Hengstler GmbH, Germany, 1999. [Online]. Available: www.hengstler.de 